\title{
El Horizonte Medio en los Andes Centrales a través de los textiles del Museo de América de Madrid*
}

\author{
María Jesús Jiménez
}

Resumen La Colección de Tejidos Prehispánicos del Museo de América de Madrid consiste en casi 400 piezas de distintos y áreas de los Andes Centrales y Centro-Sur. En este artículo nos ocupamos de aquellos adscritos al Horizonte Medio, que representan varias áreas, desde la costa sur, hasta la norte, pasando por ejemplares de estilo "Huari”, procedentes de las tierras alta. En las siguientes páginas trataremos de dibujar el complejo panorama de la producción textil de estos siglos a través de los textiles de cada región que hemos hallado en la Colección del Museo de América.

Palabras clave Tejidos, Museo de América Madrid, Análisis Técnico Textil, Regionalismos.

\begin{abstract}
The Collection of Pre-Hispanic Textiles in the Museum of America in Madrid, consists of almost 400 pieces from different periods and areas of the Central and SouthCentral Andes. In this article, we analyse those one which can be assigned to the Middle Horizon Period, representing different geographical areas from the South Coast to the North Coast, with some examples of "Huari" style from the Highlands. In the following pages, we will intent to describe the complex panorama of textile production during these centuries through the textiles of each region which have been found in the Collection of the Museum of America.
\end{abstract}

Keywords Textiles, Museo de América Madrid, Textiles Technique Analysis, Regionalisms.

* El presente artículo es una parte de la Tesis Doctoral dirigida por los Dres. Alicia Alonso y Juan José Batalla, del Dpto. de Antropología de América de la Universidad Complutense de Madrid. A ellos, y a la directora y profesionales del Museo de América, quisiera expresar mi gratitud por su colaboración. 
De entre las creaciones que los antiguos pobladores de los Andes nos han dejado, sin duda es el tejido la que ha demostrado ser la principal vía de expresión. A través de detalles como la torsión de los hilos, los colores, las técnicas y los diseños, las tejedoras y tejedores de las comunidades andinas desaparecidas expresaron su visión del mundo, de lo natural y lo sobrenatural. Pero el tejido es además una fuente de información sobre aspectos como los movimientos de poblaciones o el panorama político-territorial que caracterizó a cada uno de los momentos del largo bagaje prehispánico de estas sociedades. Es por ello que su estudio, tanto en colecciones de contexto arqueológico como de aquéllas que albergan nuestros museos, es fundamental para seguir acercándonos a esas épocas pasadas y conocerlas cada vez en más detalle.

En los últimos años he llevado a cabo el análisis de la Colección Textil del Museo de América de Madrid, como parte de las investigaciones para mi Tesis Doctoral.

Esta Colección, creada a lo largo de los tres últimos siglos a partir de los materiales traídos por expediciones científicas, donaciones y adquisiciones (Cabello 1989 y 1994; Écija y Verde 2000; Ramos y Blasco 1980: 46-51), posee casi cuatrocientos ejemplares textiles y un número indeterminado de implementos textiles y objetos relacionados con el Mundo Textil de los Andes Centrales y Centro-Sur.

El estudio técnico de estos ejemplares, así como de sus diseños y caracteres estilísticos, nos ha dado la oportunidad de acercarnos al pasado prehispánico de estas dos subregiones y ha aportado nuevas informaciones de interés.

Dentro de los periodos más complejos se encuentra sin duda el Horizonte Medio, que será el objeto de este artículo, en particular de las producciones de los Andes Centrales.

El Horizonte Medio es sin duda uno de los periodos más complejos e interesantes de la prehistoria andina y dentro del panorama textil es además uno de los que cuenta con mayor número de evidencias materiales conservadas en colecciones públicas y privadas de todo el mundo.

Se han dedicado múltiples trabajos a la producción textil de estos siglos partiendo de la idea de la existencia de patrones comunes para todas las regiones de los Andes Centrales, patrones procedentes de la sierra sur, del estilo que conocemos como Wari y cuyo centro geográfico se situó en el sitio del mismo nombre, cerca de la actual ciudad de Ayacucho (Figura 1). Este enclave fue el centro de un complejo cultural que exportó objetos materiales, conocimientos tecnológicos y una nueva estética a lo largo de los Andes. Junto con estas evidencias materiales, toda una serie de conceptos, herederos del anterior desarrollo de Tiahuanaco, impregnaron las producciones textiles de la sierra y la costa del actual Perú desde, aproximadamente, la mitad del siglo VII de nuestra era (Figura. 2). Es en la iconografía donde se aprecia esta potente carga ideológica, así como en la estética, con una marcada abstracción geométrica que expresa una manera particular de ver el mundo. El contraste se aprecia especialmente en los tejidos costeños que asimilarán -si bien en distinto grado- estas influencias serranas e introducirán en su tradicional estética realista y detallista, una notable "geometricidad" y la mencionada abstracción de diseños, cuyo origen estaba en ocasiones en la tradición local y en otras, eran manifestaciones de la ideología Wari.

Pero si hay una idea que sirva para caracterizar a la producción textil del Horizonte Medio como un todo, es la de la diversidad de interpretaciones de un mismo fenómeno: el complejo ideológico Wari.

Centrándonos ahora en los tejidos de la Colección del Museo de América pertenecientes a este periodo, podemos afirmar que ofrecen una visión bastante completa e interesante.

En la línea de lo que arriba dábamos como síntesis genérica, es posible afirmar aquí que, si bien todos los tejidos pertenecientes a esta parte del desarrollo prehispánico exhiben ciertos rasgos estilísticos comunes, bajo esa aparente homo- 


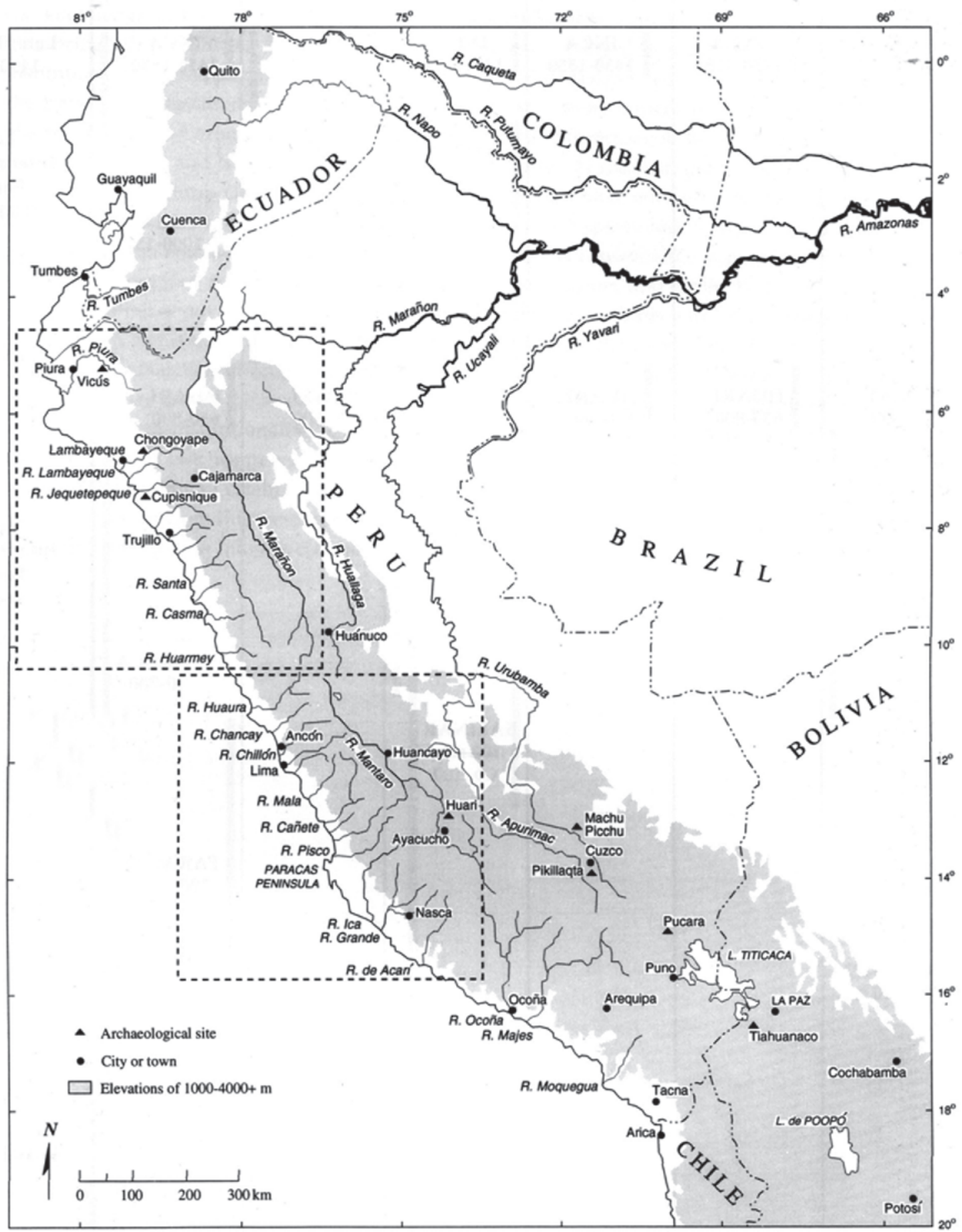

Figura 1. Mapa del Área Central Andina (Boone, ed. 1996). 


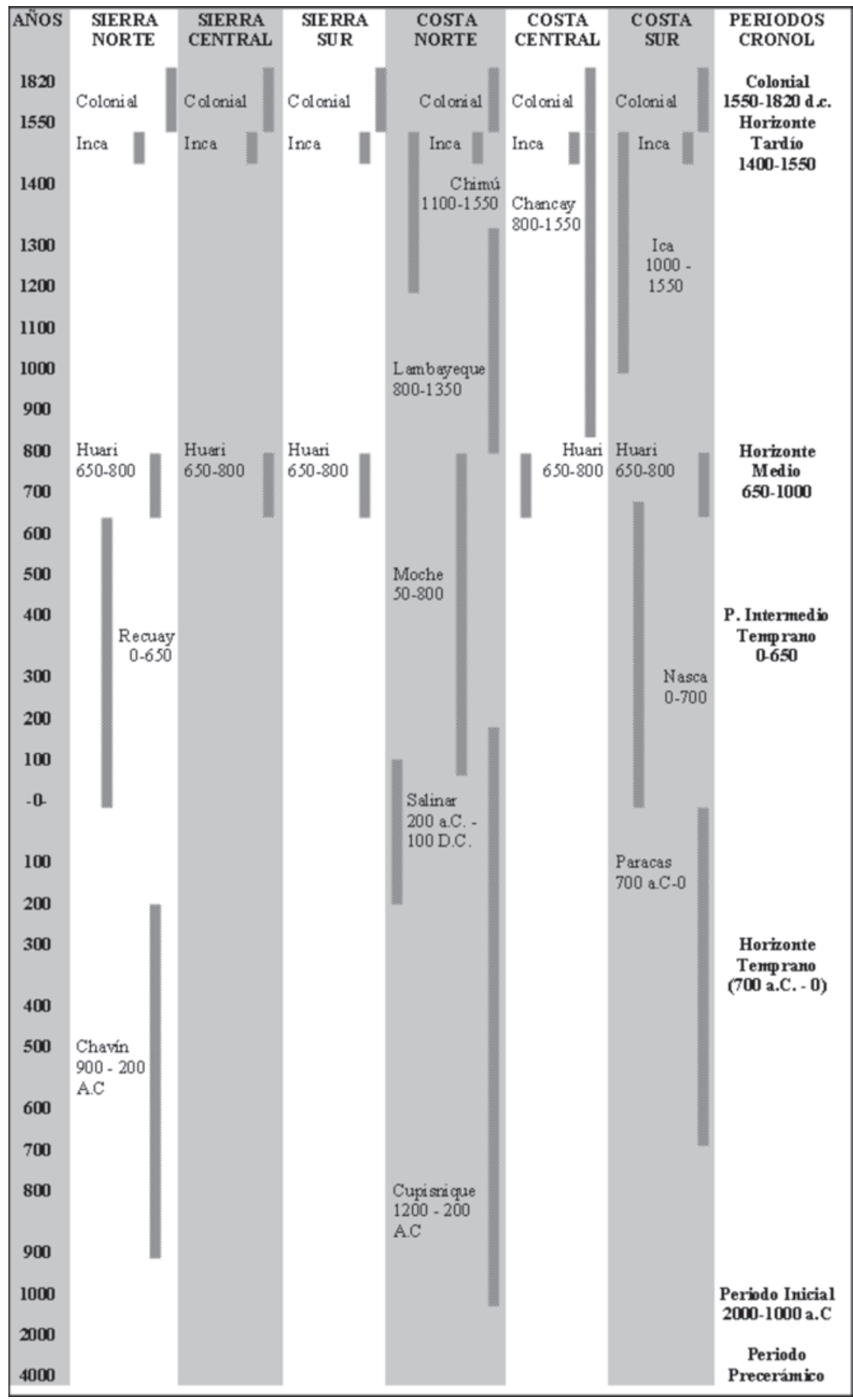

Figura 2. Cuadro cronológico del Área Central Andina (a partir de Boone, ed. 1996). 
geneidad yacen diferentes interpretaciones regionales de las influencias técnicas, estilísticas e iconográficas de Wari.

El conjunto que trataremos en este grupo incluye un total de sesenta y dos tejidos (Jiménez, en prensa: Nos. Cat. 64-118 y 123-125), pertenecientes a este periodo y asignables a diferentes variantes estilísticas: Wari, que se considera el "estilo puro" (Ibid: Nos. Cat. 64-67), las manifestaciones de la costa sur como Nazca-Wari (Ibid Nos. Cat. 68-85), los que hemos clasificado como "Horizonte Medio costa sur" distinguiéndolos de los anteriores (Ibid Nos. 86-111), Horizonte Medio costa sur o central (Ibid: Nos. Cat. 112-113), Horizonte Medio costa central (Ibid: № Cat. 114), Moche-Wari (Ibid: № Cat. $115)$ y seis piezas asignables al final del Horizonte Medio y el inicio del Periodo Intermedio Tardío fabricadas en la costa norte o siguiendo patrones norteños (Ibid: Nos. Cat. 116-118 y 123-125).

Siguiendo el orden establecido anteriormente, comenzaremos hablando de los tejidos pertenecientes a la producción de la costa sur durante este periodo, siguiendo nuestro discurso hacia el norte.

A finales del Intermedio Temprano se comienza a sentir en la costa sur centroandina la influencia de la cultura serrana Wari y este hecho se manifiesta en los tejidos. En los valles meridionales centroandinos se dio la confluencia de diferentes estilos con diferente grado de influencia serrana: Nazca Tardío y Nazca-Wari. Los primeros siguen la evolución de la tradición local, mientras que en los segundos se aprecia un mayor peso de los patrones altiplánicos. Comenzaremos hablando por los cambios que caracterizaron a Nazca Tardío.

Se produce en los tejidos de esta época en el área de Nazca un cambio sustancial en las técnicas, con el claro predominio de la tapicería, el notable descenso de los bordados y el nuevo auge de técnicas como los tejidos de urdimbres y tramas discontinuas que vimos despuntar en Nazca Temprano y decrecer en Nazca Medio. En cuanto a la calidad, comienza a apreciarse en los tejidos Nazca Medio y Tardío un descenso en la cantidad y la calidad de las producciones (Frame 1999 a: 262).

Todos estos cambios son los que dan cuerpo al estilo Nazca Tardío, aunque mantiene consistencia con muchos de los elementos que caracterizaron a aquéllos de Nazca Medio, especialmente en cuanto a la iconografía. Muchos motivos anteriores, como el Ser Mítico (comparar, por ejemplo, Silverman y Proulx 2002: fig. 2.1 y № Cat. 60, véase foto detalle) seguirán apareciendo en las telas de esta época, aunque con importantes transformaciones estilísticas. Si bien "Nazca Tardío" es la denominación más generalizada, se sigue utilizando el término "Prolífero" acuñado por Dawson (Silverman y Proulx ibid: 22, Tabla 2.1), razón por la cual lo hemos incluido en las Fichas de Catálogo. A continuación comentaremos aquí los tejidos tardíos de nuestra muestra como la última manifestación "propiamente Nazca".

La Colección del Museo de América posee en total catorce ejemplares asignables a este estilo, de los que trece (Nos. Cat. 49-51 y 53-62) ${ }^{1}$ pertenecen al estilo Nazca Tardío y uno (№ Cat. 52) es claramente contemporáneo y asignable a la misma región, aunque sus rasgos no son propiamente Nazca Tardío.

Desde el punto de vista tecnológico y tipológico hemos de destacar la presencia en esta muestra de tres piezas cuya forma es en principio difícil de identificar. Nuestro estudio bibliográfico permite, no obstante, identificarlas con lo que se ha llamado "borlas" que formaban los extremos de tocados masculinos y que colgarían probablemente a ambos lados de la cara (Figura 3). Estas borlas son quizá el elemento más característico

\footnotetext{
${ }^{1}$ Los números a los que se hará referencia en repetidas ocasiones en este trabajo corresponden al Catálogo extraído de esta Tesis y que será publicado próximamente (Jiménez, en prensa)
} 
de la producción textil Nazca Tardío y han sido extensamente estudiadas por Mary Frame (1986b y 1996). Su compleja técnica, denominada "sprang" (Emery 1980: 66-69) y lo particular de su forma, uso y diseños, hace que destaquemos su presencia en nuestra muestra, ya que constituyen una muestra singular de la exploración técnica de los antiguos tejedores andinos, así como de la particularidad de la indumentaria masculina de este periodo en el área costera meridional.

Los ejemplares que documentamos aquí evidencian la existencia de varios niveles de complejidad en los diseños y la elaboración técnica en general, especialmente si los comparamos con otros ejemplares publicados, como los de la colección Dumbarton Oaks (Frame 1996). Al mismo tiempo, demuestran que existió una gran estandarización en la fabricación de estas piezas, en lo que a medidas, forma y conjunto general de rasgos se refiere. Lamentablemente han llegado hasta nosotros de forma incompleta.

Junto con las borlas en sí, existen en la Colección del Museo de América tres conjuntos compuestos respectivamente por varios fragmentos de tejido tubular (Nos. Cat. 56-58) que pertenecieron originalmente a los largos cordeles de atado de borlas de este tipo. No obstante, no hay evidencias claras que nos permitan asociarlos directamente con las borlas citadas, si bien, completan la visión de este particular ítem textil.

La Colección del Museo de América incluye varios tejidos en forma de banda que constituyen otro tipo Nazca Tardío, probablemente destinadas a decorar prendas quizá de algodón lisas. Entre ellas, sin duda los Nos. Cat. 60 y 61 constituyen ejemplares excepcionales por la extraordinaria finura de su factura (Figura 4). Frame (1999 a: 296, lám. 21) las ha caracterizado apuntando a ellas como uno de los elementos típicos de la textilería tardía de Nazca. La técnica de tapiz de ranuras utilizando en algunos casos el mecanismo denominado dovetailing para cerrar las aberturas, así como una gama cromática muy específica (fondo rojo, diseños en amarillo, azul, etc, con delineados en colores varios) y el diseño del Ser Mítico con una gran máscara y adornos faciales, son los elementos que caracterizan habitualmente estas bandas, de extraordinaria finura y calidad. Uno de nuestros ejemplares se conserva completo, su forma y longitud $(202 \mathrm{~cm})$ nos permiten proponer que las prendas que decoraban debían ser mantos de grandes dimensiones, probablemente compuestos por una tela llana monocroma, que se ha perdido o que pudieron haber sido desechados en el momento de su hallazgo. Estos grandes mantos parecen ser herederos de la tradición Paracas.

Es importante destacar que hasta el momento no se habían documentado bandas de este tipo completas que nos permitieran hacernos una idea de la existencia y aspecto de estos mantos. Se trata de uno de los importantes aportes de la Colección del Museo de América al conocimiento del estilo textil Nazca.

Ya mencionamos anteriormente el descenso de calidad de los tejidos Nazca Tardío que podemos observar también en algunos ejemplares de nuestro conjunto, como los Nos. Cat. 49, 50 y 51 , cuyo acabado, algo más tosco, contrasta con el de las bandas anteriormente analizadas, con las que, por otra parte, mantienen semejanzas. En ellos podemos apreciar también otro de los rasgos que comenzamos a observar aquí y que se perpetúan durante el Horizonte Medio en los textiles Nazca-Wari: el grueso delineado de las figuras y la alta abstracción de su representación, que en ocasiones hace difícil su identificación. Ambos elementos pueden interpretarse como influencias procedentes de las tierras altas, en los albores del Horizonte Medio.

Por último, para ilustrar otro aspecto importante de estas producciones, cabe mencionar el ejemplar № Cat. 62, un fragmento en técnica de tramas y urdimbres discontinuas con diseños de escalonados. Esta técnica parece recuperar gran parte de la importancia que tuvo en Nazca Temprano (A.P. Rowe 1972). Frame (1999 a: 298-300) se refiere a tejidos de este tipo encon- 
trados en tumbas de las Fases 7 y 8 de Nazca en Chaviña y Cahuachi (área de Nazca) que se fabricaron probablemente para adornar muros de tumbas o edificios. Esta referencia da más firmeza a la clasificación de nuestro ejemplar, que presenta además una gama cromática terrosa, acorde con las tendencias del Horizonte Medio.

En conjunto los tejidos Nazca Tardío muestran innovaciones técnicas y estilísticas notables que se combinan con elementos de la tradición regional de estos valles meridionales.

Ya entrado el Horizonte Medio, se desarrollan en la costa sur los tejidos Nazca Wari, con ejemplos como el material textil documentado por A.P. Rowe (1986) que formaba parte de varios contextos funerarios excavados en el sitio de Monte Grande (Valle de Nazca). En ellos, tejidos de filiación Nazca-Wari se hallaron en el mismo fardo con otros que podemos considerar "Wari puro".

En lo que respecta a Nazca-Wari, podemos decir que si bien conserva algunos elementos pertenecientes al estilo regional de Nazca que vimos anteriormente, lo más característico es el modo en que los fusiona con rasgos serranos. La muestra que presentamos posee los Nos. Cat. 68-85.

En nuestro análisis hemos puesto atención en esa dicotomía de pervivencias locales y transformaciones y, tras la observación detenida de este conjunto, podemos concluir que la tipología de las prendas es quizá el elemento menos permeable a los cambios dentro del conjunto de patrones textiles. Así, hemos podido comprobar que las camisas (Figura 5) (№ Cat. 73) y las bolsas (Nos. Cat. 68, 71 y 72) (Figura 5) de estilo Nazca-Wari siguen manteniendo la forma y el modo de fabricación del estilo Nazca.

Los cambios que caracterizan a Nazca-Wari frente a las manifestaciones Nazca Tardío se incorporan en elementos técnicos, como la mayor utilización de fibra de camélido y técnicas, especialmente el tapiz entrelazado (interlocked tapestry, Emery 1980: 80-81) y sobre todo, nuevos motivos iconográficos y rasgos estilísticos, como muestran los Nos. Cat. 68, 71 y 72. Estos nuevos elementos del diseño consisten en la adición de volutas o ganchos a las figuras y un delineado grueso de las mismas. Los hemos encontrado en los motivos de camisas (véase Figura 5) (№ Cat. 73), bolsas y bandas (№ Cat. 70), o lo que hemos identificado como un posible muestrario (№ Cat. 69) ${ }^{2}$. En relación a éste último, es destacable la técnica de bordado "al pasado" o (double running stitch, Emery 1980: 235) que según Frame (1999a: 294) comenzó como uno de los cambios inducidos por la influencia serrana en los tejidos Nazca Tardío y se mantuvo durante el Horizonte Medio, hasta convertirse en el tipo de bordado más común en este periodo (Frame 1999b: 318). Aquí lo observamos en otras piezas como la bolsa con el № Cat. 71 .

Una variedad técnica que resulta finalmente muy similar a estos bordados es la de los tejidos fabricados en tela llana sobre la que se insertan tramas suplementarias que cubren toda la superficie y asemejan un tapiz (ver Nos. Cat. 83-85). Este tipo de tejidos no tiene precedente en el estilo Nazca anterior y constituye uno de esos ejemplos de particularismos regionales que surgen en la costa meridional junto con Wari. La misma técnica, se da especialmente en este periodo. En concreto, A.P. Rowe (1979: 186) denomina a estos textiles "tejidos de tramas discontinuas parecido al tapiz" (discontinuous wefts resembling tapestry) y sitúa su generalización en la costa sur a partir de la segunda parte del Horizonte Medio en sustitución de la técnica de tapiz que será más escasa a partir de esos momentos. Se trata de piezas cuadrangulares o rectangulares, en su mayor parte mantos o paños envoltorios, con esquinas decoradas utilizando la técnica descrita y con diseño de clara influencia serrana, encerrados en

\footnotetext{
2 Se trata de pequeño fragmento de tejido en el que se han representado tres diseños que no guardan relación entre sí ni forman una composición coherente, razón por la que hemos propuesto tentativamente que se trata de un muestrario.
} 
matrices cuadrangulares. El color es un elemento fundamental en estas piezas, y los juegos cromáticos creando ejes diagonales mediante alternancias rítmicas son muy comunes en ellos. Este tipo de tejidos pareció originarse en el valle de Nazca de donde proceden todos los ejemplares con documentación arqueológica o datos de procedencia (Harcourt 1934: 126, Pl. VII; O'Neale y Kroeber 1930: 55, Pl. 21 a). Muchos otros ejemplares se han documentado pero no se poseen datos concretos sobre su origen, por lo que se asignan a este estilo dada la homogeneidad de sus patrones (Bird et. al. 1981: 91; Schlindler 2000: 122-123; Solanilla 1999: 158-159, no 88; 142 143, n 77 ). Como decíamos, la iconografía es de origen serrano, como evidencia la aparición en alguno de los ejemplos publicados (Harcourt 1962: 126, Pl. VII), del denominado "Felino Atarco" documentado también en la cerámica Horizonte Medio 2b (Menzel 1964: figs. 11 a, 19 y 20) y presente en algunas de ellas. Junto con ésta, otras figuras como el llamado humped animal o figuras de lo que podrían ser camélidos ( $\mathrm{n}^{\mathrm{O}}$ Cat. 83), forman parte del repertorio característico de estas piezas.

Dentro de este tipo de tejidos planos con esquinas decoradas mediante patrones escalonados, A.P. Rowe (1986: 160-161) documenta otra variante cuya técnica más usual es la de tramas suplementarias o "brocado" (supplementary wefts, Emery 1980: 140-143). En este caso, el estudio de varios fardos funerarios del ya mencionado sitio de Monte Grande (valle de Nazca) así como de otros tejidos relacionados pertenecientes a la colección del Textile Museum de Washington, ha permitido a A.P. Rowe clasificar estas piezas con esquinas decoradas dentro del estilo Nazca-Wari, asegurando su filiación con piezas procedentes de contexto. En su opinión, las prendas con esquinas decoradas podrían tener su origen en Nazca Tardío y cita una tumba saqueada que fue excavada por UbbelohdeDoering, en la que se encontraron piezas que serían los prototipos de las que después se incluyeron en contextos junto con piezas Wari (A.P.
Rowe 1986: 157-158). Junto con los de esta autora, algunos otros ejemplos (Frame 1990: 5) muestran la forma, dimensiones y morfología en general que tuvieron estos tejidos en origen.

En nuestra colección los Nos. Cat. 80-82 ilustran este otro tipo de esquinas decorativas, una de estas piezas con el valor añadido de encontrarse aún en el bulto funerario al que perteneció la momia Nazca-Wari con el № Cat. 79. Esta pieza se conserva además completa y nos da una pista de una de las funciones que estos paños de esquinas decoradas pudieron tener, al estar colocada a modo de velo. No obstante, dada la variación en los tamaños y tipos de decoración de los ejemplares de esquinas decoradas, es razonable pensar que sus usos pudieron ser variados. Este "velo" tiene además un rasgo muy importante que nos permitió clasificarlo y con él al bulto completo, dentro del estilo que estamos comentando e incluso proponer que procede del valle de Nazca. Se trata de la presencia en los orillos de urdimbre de tres pasadas de algodón grueso en color azul. (A.P. Rowe 1986: 158-159). Este ejemplo pone de manifiesto que cualquier detalle técnico, por insignificante que parezca, puede aportar datos definitivos que nos permitan contextualizar adecuadamente no sólo un tejido sino, como en este caso, todo un conjunto.

La notable estandarización que muestra este tipo textil "de esquinas decoradas" podría indicar que esta producción se concentró en el valle de Nazca y alrededores, donde, como hemos visto, se han documentado la mayor parte de los ejemplares de los que existen datos de procedencia.

Los Nos. Cat. 74-78 forman un grupo variopinto asignado a este estilo por asociaciones, como la bolsa № 75 con el conjunto de Monte Grande mencionado o por una conjunción de datos técnicos e iconográficos que los ponen en relación con el precedente estilo Nazca, no obstante, son menos ilustrativos de las tendencias generales.

Quizá también en este valle se fabricaron algunas de las manifestaciones del siguiente esti- 
lo que comentaremos, el llamado "Wari" y que podemos considerar como el "modelo" a partir del cual se produjeron las interpretaciones regionales que dan forma al compendio de la producción textil sureña de este periodo.

A pesar de que el origen de este estilo textil se encuentra en las tierras altas, las lluvias estacionales que caracterizan al clima serrano hacen casi imposible la preservación de tejidos, de forma que aquéllos considerados de procedencia y filiación estilística Wari se han hallado en la mayoría de las ocasiones en contextos de la costa sur, como el ya mencionado de A.P. Rowe $(1986)^{3}$. Junto con los tejidos de este estilo fabricados en las tierras altas, se encuentran los que se tejieron en la costa siguiendo los patrones serranos. En muchos casos la morfología y la iconografía de las camisas Wari de la costa y la sierra son idénticas. El elemento que permite diferenciarlas y por tanto establecer cuál es una importación y cuál es una "copia" de producción local, es la materia prima, ya que en la sierra se tejió utilizando únicamente fibra de camélido, mientras que en la costa se usó algodón para los hilos que quedaban ocultos, en este caso, los de la urdimbre.

Nuestro análisis revela que la Colección del Museo de América incluye las dos opciones: los ejemplares fabricados en la costa como "copias" de los serranos, junto con las importaciones llegadas desde las tierras altas.

Los primeros cuentan, como indicábamos, con urdimbres de algodón. El hecho de que el resto de los patrones técnicos e iconográficos reproduzcan exactamente los modelos serranos puede quizá explicarse por la presencia de tejedores serranos desplazados a los valles, como sugiere Cook (1996: 88), o bien por la posibilidad de que el algodón fuera eventualmente importado en las tierras altas para algunos ejemplares. A nosotros nos parece más acertada la primera de las explicaciones, que es además consistente con el intenso flujo de poblaciones que se movió por distintas áreas de los Andes en esta época.

Junto con los tejidos de estilo Wari fabricados en la costa, los manufacturados en la sierra están fabricados con fibra de camélido en tramas y urdimbres y fueron probablemente llevados como objeto de intercambio o regalos a los valles desérticos del sur. Se trata de una camisa masculina completa y un fragmento también de camisa, un tipo de prenda que formó parte habitualmente de este tipo de regalos y en general del flujo de tejidos en el Horizonte Medio.

El estudio de Cook (1996) ha revelado la importancia de la indumentaria masculina en las relaciones interétnicas existentes e intracomunitarias durante el Horizonte Medio. Basándose en el estudio de los denominados "huacos efigie" que representarían a altos dignatarios Wari (Fig. 6), esta autora establece que los gorros de cuatro puntas decorados en su base con rombos cuatripartitos estuvieron reservados a las élites de la administración Wari, así como determinadas camisas. Entre ellas esta autora incluye, tanto las piezas en técnica de tapiz (Emery 1980: 78-81), como los tejidos de urdimbres y tramas discontinuas (discontinuous warps and wefts) (A.P. Rowe 1977: 25-33; Strelow 1996) con decoración de "atado y teñido" o tye-dyed. Así pues, estas dos prendas se convierten además en distintivos de rango, eso sí, en base a sus diseños y con independencia de su lugar de fabricación.

En lo que respecta a las camisas de tapiz, completas o fragmentarias, analizadas por nosotros en esta Colección (Nos. Cat. 64-67, Figura 7), hemos de constatar que no existen diferencias en cuanto a la calidad, métodos de elaboración ni ningún mecanismo tecnológico entre las fabricadas en la costa y aquéllas tejidas en las tierras altas. Sólo poseemos información sobre la procedencia de una de ellas (№ Cat. 65) un fragmento de túnica costeña que, sin embargo procedería, según estos datos, de "los alrededores de

\footnotetext{
${ }^{3}$ Existen, no obstante, ejemplares de este estilo que llegaron a otros enclaves costeños, como la camisa que ilustra Menzel (1977: fig. 75), procedente de Chimú Capac, en el valle de Supe.
} 
Tiahuanaco". Si bien es cierto que es más común que prendas serranas bajaran a la costa, es posible que ésta llegara a las tierras altas como fruto de intercambio. Lo extraño de su buena conservación, sin embargo, hace que tomemos este dato con cierta reserva.

Las numerosas similitudes entre prendas serranas y costeñas refuerzan la hipótesis antes mencionada sobre la presencia de artesanos especialistas serranos en las tierras bajas, que se adaptaban a los patrones costeños usando el algodón para las urdimbres en una región en la que la fibra animal constituye un bien escaso y preciado. Junto a este elemento, habrían introducido la variedad entrelazada del tapiz (típica de la sierra frente a la ranurada costeña), así como el uso de un telar vertical más adecuado para este tipo de piezas (Bird y Dimijitrevic 1974). Todo ello supone, en definitiva, un conjunto de prácticas que dan cuerpo a la tradición textil de la sierra que se había ido forjando durante siglos y que durante este periodo es trasladada a lo largo de la costa centroandina.

Junto a estos patrones técnicos, los diseños representados en los tejidos analizados por nosotros muestran una gran influencia de la estética y las ideas serranas. Éstos se caracterizan por una notable abstracción y la utilización de efectos de color y ritmo mediante la combinación de formas geométricas. Todo ello, según Cook (1996) perseguía comunicar visualmente una serie de significados referentes al rango de aquél que la vestía.

Al hilo del trabajo de Cook comentaremos a continuación otro conjunto de piezas de esta colección, trabajadas en técnica de "atado y teñido" (Nos. Cat. 87-90). Estas prendas merecen un comentario previo sobre su clasificación estilística. Ya hemos mencionado que aparecen representadas en los "retratos" cerámicos de personajes Wari de alto estatus, lo que indica su relación con el estilo Wari. Por otro lado, no es infrecuente encontrarlas clasificadas como "NazcaWari”, si bien no poseen de hecho ningún elemento que permita ponerlas en relación con el estilo textil Nazca. Lo que sí parece claro es que es una producción distintiva de los valles sureños de la costa centroandina que surgió probablemente como mezcla de elementos regionales con influencias Wari (Frame 1999b: 336-341). En base a ello, nosotros las hemos clasificado dentro del grupo "Horizonte Medio costa sur", que establece las dos premisas de las que se tienen datos fundados en la actualidad. Esta es la tendencia que siguen también autores como Frame (ibid) y que encontramos en la Colección de Dumbarton Oaks (Conklin et.al. 1996).

Varios ejemplares de camisas y mantos (completos y fragmentarios), decorados con esta técnica, forman parte de nuestro conjunto (Nos. Cat. 87-91) y amplían nuestra visión de la indumentaria de élite de los "funcionarios" Wari.

En la técnica de "atado y teñido" el color es el principal elemento de expresión y la fibra de camélido (abundante en las tierras altas), la que ofrece mayores posibilidades al tintorero, a diferencia del algodón costeño que presenta muchas dificultades para ser teñido. Es razonable pensar, por tanto, que tiene también origen serrano y habría comenzado a darse en la costa a partir de este periodo, del mismo modo que las camisas a consecuencia de la influencia Wari.

El modo de elaboración es similar para ambos tipos de prendas, camisas y mantos. La tela base es de tramas y urdimbres discontinuas, cuyo antecedente se encuentra en las primeras fases de Nazca (A.P. Rowe 1972). Se forman así unidades de variadas formas a modo de pequeñas piezas rectangulares o con forma escalonada, que se fabrican en grupos y se tiñen "por reserva", esto es, amarrando con cordeles determinadas áreas de la tela antes de sumergir ésta en el tinte. La tela así tratada resultaba con dos áreas de colores distintos: no atada que se teñía y la atada en la que se preservaba el color de la tela base al haber sido cubierta por los cordeles. Posteriormente, las piezas o grupos de piezas se enganchan entre sí formando una composición decorativa compleja a partir de la variedad de decoraciones de cada grupo. Se utiliza por ello en ocasiones el término anglosajón de patchwork 
para referirse a estas "telas hechas de parches". Este modo de elaboración da como resultado composiciones caracterizadas por alternancias rítmicas de colores y formas que parecen responder a los mismos principios y conceptos de las composiciones de las camisas de tapiz.

En nuestra muestra hay una camisa completa junto con un pequeño fragmento también probablemente de camisa, un manto completo y uno fragmentario y una pieza que, por sus dimensiones, hemos considerado parte de otro manto. Llama la atención la variabilidad en la forma de las piezas que constituyen las diferentes prendas, desde los escalonados y los rectángulos a la larga tira (№ Cat. 91) del manto. También es variable la decoración en sí, con múltiples combinaciones de formas básicas (cruces, líneas diagonales, etc) que se forman a base de motivos romboidales. Estas variaciones contrastan con la uniformidad técnica: utilización casi exclusiva de fibra de camélido salvo el uso marginal de algodón en los remates de urdimbre de alguna de ellas, técnica de elementos discontinuos (salvo en la camisa № Cat. 87) y gama limitada de colores.

Siguiendo con los tejidos "Horizonte Medio costa sur" y con la indumentaria de los personajes de élite, tenemos los llamados "gorros de cuatro puntas", sin duda, entre los objetos más característicos de la producción andina prehispánica. Su forma y técnica de construcción los hacen diferentes a cualquier otro tipo de prenda y su restringida ubicación en el espacio y el tiempo hacen de ellos elementos diagnósticos de la presencia Wari en un área geográfica o en el conjunto de una colección como ésta.

Proceden mayoritariamente de contextos de la costa sur, aunque están elaborados con fibra de camélido y los diseños son de tradición altiplánica. Están hechos con una técnica muy característica, que consiste en una estructura anudada que en ocasiones forma diseños mediante cam- bios del color de la fibra, mientras que en otros casos es monocroma pero lleva inserta fibra de colores a modo de terciopelo ${ }^{4}$ con el que se elaboran variados diseños. El estudio de Mary Frame (1990) sobre los gorros de cuatro puntas ha revelado que los primeros fueron fabricados en la sierra, mientras que los de aspecto "aterciopelado" proceden de la costa.

En la muestra que hemos analizado se incluyen dos ejemplares de estos gorros (Nos. Cat. 92 y 93) (Figura 8) que, siguiendo las conclusiones de Frame, pertenecen a la producción costeña. Muestran una elaborada técnica de fabricación y compleja iconografía y tienen paralelos en otros ejemplares documentados (Berenguer 1993; Cornejo 1993; Desrosiers y Pulini 1992: 19, fig. 5 y 116-117, fig. 6; Harcourt 1962: 164-165, Pls. 72 y 73; Frame 1990; O'Neale y Kroeber 1930: pl. 26; A.P. Rowe 1986: 161-162, fig. 38; Schlindler 2000: 128-131, Stone-Miller, ed 1994: 112, Pl. 27, Ulloa 1985: 35-37, etc).

El estudio de la iconografía de los dos ejemplares del Museo de América es esclarecedor, ya que indica, de acuerdo con la interpretación de Cook que desarrollamos anteriormente, que representan respectivamente dos distintos niveles de rango en la organización socio-política Wari. Uno de ellos (véase Figura 8), habría pertenecido a un gobernante, tal y como indica la banda inferior de rombos cuatripartitos que está acompañada, además en su parte superior, una figura antropomorfa alada con atributos felínicos que pudo estar representando a una deidad. ${ }^{5} \mathrm{El}$ otro probablemente perteneció a un individuo destacado en su comunidad, con acceso a recursos, aunque no necesariamente relacionado con la organización política.

Merece siquiera una breve mención el № Cat. 94, consistente en un largo cordel fabricado en la misma técnica y colores de estos gorros, pero cuya función y origen no están claros.

\footnotetext{
${ }^{4}$ Para una explicación técnica ver Stone-Miller, ed (1994: 112).

${ }^{5}$ El ejemplar que documentan Desrosiers y Pulini (1992: 19, fig. 5 y 116-117, fig. 6.) tiene esta misma figura.
} 
Otros elementos del atuendo de este periodo están representados en nuestra Colección con ejemplares como las vinchas o bandas de cabeza (Nos. Cat. 106-108), fabricadas en la costa, adoptando la estética y la iconografía serranas con patrones costeños de manufactura. Al menos dos de ellas tienen urdimbres de algodón, que indica origen costeño. En la tercera no fue posible ver la urdimbre, pero dada su similitud y el hecho de que llegaron como un conjunto, podemos suponer el mismo origen. Por otra parte, la técnica en que están trabajadas es la de tapiz de ranuras (slit tapestry, Emery 1980: 78-80) característica de los valles costeros.

Como tendremos oportunidad de comprobar en las siguientes páginas, los adornos y atuendos de cabeza parecieron cobrar especial importancia en este periodo, como se observa en la variedad de tipos y en su fina elaboración.

Podemos destacar, por tanto, que los tejidos de estilo Wari del Museo de América nos muestran las manufacturas de origen serrano y costeño, poniendo en evidencia que las diferencias entre ambas se reducen a la utilización o no de algodón. La iconografía, los símbolos y los procedimientos técnicos se reprodujeron en el "centro" y la "periferia" de forma casi indistinguible.

El siguiente grupo de tejidos de este periodo y que hemos incluido dentro de las producciones del Horizonte Medio en la costa sur lo forman 19 ejemplares (Nos. Cat. 86 y 94-111). La mayor parte de ellos no tiene procedencia conocida. En un caso (№ Cat. 96) tenemos datos que lo sitúan en Nazca, aunque ni técnica ni estilísticamente puede relacionarse con el estilo Nazca-Wari y no existen paralelos con contexto de este tipo donde se hallen piezas del tipo que describiremos, razón por la cual se incluyen en este grupo. Los tejidos que lo forman se caracterizan por la fusión de elementos de la tradición costeña meridional y una importante influencia serrana en la iconografía y los elementos técnicos.

Tenemos un grupo de piezas con forma de banda que parecen haber sido remates decorativos de camisas u otras prendas (Nos. Cat. 101.
105) probablemente elaborados aparte y después cosidos a los extremos de las mismas. Predomina la misma técnica de tramas suplementarias imitando tapiz que A.P. Rowe (1979:186) sitúa a partir de la mitad del Horizonte Medio, aunque se utilizan también las tramas complementarias para la franja decorativa central y el tapiz de ranuras con dovetailing. Se repiten también muchos de los diseños que vimos antes en los tejidos con esquinas decoradas, como el "Felino Atarco" y el estilo geometrizante de Wari, aunque en algunos ejemplares se vaya vislumbrando cierto "realismo" que será más característico en el siguiente Periodo Intermedio Tardío (Nos. Cat. 101 y 102). Muchos presentan una costura burda en uno de sus extremos que podría indicar que fueron fabricados en serie en un mismo telar y posteriormente cortados y rematados. Son consistentes en poseer un color predominante rojorosado, oscuro y los motivos en tonos amarillo, blanco, negro, verde y azul, siendo este tono destacable ya que, como afirma Frame (1999c: 332) es típico de los estilos de la costa sur con influencia serrana. A pesar de que los datos que poseemos sobre la procedencia de dos de ellos los sitúan en el valle de Supe, en la parte norte de la costa central centroandina (véase Fig. 1), el resto de los rasgos de su manufactura apunta a una clara procedencia sureña. Su hallazgo en la costa central indicaría, en nuestra opinión, que estas piezas fueron objeto de intercambio entre comunidades de los distintos valles costeros. Es el mismo caso que el № Cat. 111 decorado con la llamada "Águila de Pachacámac" y del que Desrosiers y Pulini (1992: 20, fig. y № 7) documentan un fragmento idéntico, procedente de la Necrópolis de Ancón, pero que ellas indican debió fabricarse en el valle de Ica y viajar como producto de intercambio hacia el norte.

También en los valles sureños se sitúan unas piezas muy emparentadas con las anteriores y que hemos identificado como bandas de cabeza (Nos. Cat. 96 y 98). Poseemos datos de procedencia de la primera de ellas, que la sitúan en el valle de Nazca. Se trata de un ejemplar cuya com- 
pleja técnica de urdimbres complementarias es típica de la sierra. Su iconografía hace referencia al culto conocido como del "Dios de los Báculos" que tiene en la iconografía de la Puerta del Sol de Tiahuanaco su más conocida representación y sigue un esquema cromático similar al del grupo de las bandas-remate decorativas comentado, especialmente en lo que respecta al fondo rojo oscuro y diseños en colores como verde, blanco, morado oscuro y el mismo rojo. Es interesante que la primera de las dos que aquí presentamos tiene tramas de algodón, que indica un origen costeño y confirma los datos de procedencia. Por su parte, la segunda está tejida completamente con fibra de camélido indicando que pudo haberse tejido en las tierras altas y llegar a la costa por intercambio. Nosotros hemos tenido oportunidad de analizar una banda casi idéntica, completa, en la Colección Maiman (Makowski et.al., en prensa) que estaba también fabricada con tramas y urdimbres de fibra de camélido. Se produce, por tanto, el mismo fenómeno que vimos con las camisas de tapiz Wari, con la existencia de dos focos de fabricación o bien de artesanos serranos desplazados a la costa sur junto con la importación de fibra de camélido.

Estas bandas de cabeza vuelven a ponernos en relación con las mencionadas vinchas y los gorros de varios tipos que hemos analizado en esta colección. Estos elementos actuando como identificadores étnicos y de estatus aparecen de forma recurrente durante este periodo.

La misma iconografía y gama cromática que encontramos en las bandas de cabeza la encontramos en otro grupo de piezas, todas en estado fragmentario, que hemos clasificado también como "Horizonte Medio costa sur". Su función no está clara, la orientación de sus figuras indica que podrían haber sido bandas, aunque su anchura es mayor que la de las anteriores. Se trata de los Nos. Cat. 97 y 99. En este caso, la técnica de tela llana con tramas suplementarias semejando tapiz las sitúa en la costa sur en la segunda parte del Horizonte Medio (A.P. Rowe 1979: 186) y la iconografía (Figura 9) nos remite de nuevo al culto altiplánico que habría llegado a la costa sur por medio de la expansión de las ideas Wari.

Los Nos. Cat. 86. 95, 109 y 110 pertenecen al mismo grupo de "Horizonte Medio costa sur", aunque muestran caracteres, tanto técnicos como estéticos, contrastados entre sí y con el resto de los ejemplos ilustrados anteriormente. No obstante se puede señalar que los diseños que se observan en los fragmentos 95 y 110 pueden interpretarse como representaciones de estructuras textiles en la misma idea defendida por Frame (1986). En el primer caso (№ Cat. 95), las dos hileras de lo que aparentemente son rombos, están representando dos elementos que se entrelazan como hilos y que pasan alternativamente por encima y por debajo del contrario. Lo mismo ocurre con los rombos del fragmento № Cat. 110. Todo ello pone en evidencia la importancia del proceso tecnológico textil en la cultura andina prehispánica.

Los cuatro ejemplos arriba mencionados ilustran la gran variabilidad existente en las manifestaciones de este periodo en la costa sur, una de las características más destacables del Horizonte Medio.

El último grupo que mencionaremos es el de los tejidos de plumas, de los que poseemos dos espléndidos ejemplares pertenecientes a este periodo (Nos. Cat. 243 y 244).

Lo más destacable de la producción plumaria en los Andes Prehispánicos es la notable estandarización de los procedimientos técnicos seguidos e incluso de la materia prima utilizada. El algodón es la fibra utilizada siempre en la base, las plumas se añaden utilizando un método ilustrado por varios autores (Figura 10). Las plumas eran obtenidas de la selva, lo que indica la existencia de contactos a larga distancia con estas lejanas tierras con las que se intercambiaban productos siguiendo la estrategia de complementariedad tan importante para entender la prehistoria andina. Así, los tejidos de plumas se convirtieron en objetos de lujo que, en el caso de las prendas, como puede haber sido el № Cat. 243, 
estaban reservadas probablemente a miembros de la comunidad con acceso a recursos, pasando a ser en un distintivo de estatus. En otros casos, como el № Cat. 244 grandes paneles ricamente labrados con plumas de vivos colores se podrían haber utilizado para colgarse en las paredes de las tumbas, en una nueva exhibición de poder y riqueza del individuo para el que estaban destinados.

Más allá de la consideración de las plumas como bien escaso y por tanto, de lujo, conviene prestar atención a las connotaciones simbólicas que éstas debieron tener. Boysse-Cassagne (1997) analiza la importancia de las plumas entre los Incas y señala el marcado simbolismo que tuvieron al relacionarse con sus mitos de origen y su vinculación con el área del Titicaca y los complejos Tiahuanaco y Wari. Esta vinculación nos parece muy interesante por cuanto podría explicar la marcada estandarización de los modos de fabricación de estos tejidos en un área como la andina, donde el propio medio favorecería la compartimentación y el empleo de múltiples variantes de un mismo procedimiento. En nuestra opinión, la fabricación de tejidos de plumas pudo tener su impulso definitivo o incluso su origen, en el Horizonte Medio, de la mano de Wari, estando la producción centralizada y controlada por el poder. Los tejidos de plumas habrían sido, como después serán con los Incas, un bien altamente valorado, utilizado como regalo y distintivo especial, dentro de la política de alianzas y el juego de mutuas reciprocidades entre el centro político de Wari y los líderes de las distintas organizaciones regionales. Quedaría por determinar la razón por la que la producción de estos tejidos se situó en la costa y no en la sierra tal como indica el uso único de algodón en la base. Los valles sureños, cuya relación con el área de la sierra fue siempre estrecha, albergaron esta producción que, como en otros casos gorros de cuatro puntas, bandas..., debió estar a cargo de un grupo de artesanas especializadas o incluso de comunidades que se centraron en la obtención de recursos y fabricación de estos preciados objetos.
En definitiva, en la costa sur el Horizonte Medio constituye una época caracterizada por una gran variedad en la producción textil. Se produce la convivencia de diferentes tipos textiles que muestran distintos grados de mezcla de elementos costeños y serranos. La presencia en la costa de piezas manufacturadas, en la sierra evidencia que se dieron intensos intercambios de objetos y movimientos de pobladores.

Dentro de esa variabilidad, tuvo cabida, no obstante, una producción organizada de ciertos tejidos de lujo, como camisas de tapiz, gorros de cuatro puntas o prendas de "atado y teñido", como demuestra la consistencia de sus procedimientos técnicos y diseños en un gran número de ejemplares en esta colección a la que se añaden los distribuidos en otras alrededor del mundo.

Precisamente estos tejidos más lujosos habrían estado destinados a los miembros más poderosos dentro de la organización social y política del área, algunos incluso vistiendo prendas que directamente los identificaban con el poder, como las camisas de tapiz o "atado y teñido", con diseños de escalonados y los gorros de cuatro puntas.

Seguramente fueron estos individuos también los destinatarios de la producción de plumaria, para la cual se mantuvieron redes de intercambio a larga distancia, probablemente con intermediarios serranos a cambio de productos costeños, como pescado o algodón.

Los contactos entre comunidades que se evidencian en el estudio de tejidos de la costa sur y que la Colección del Museo de América ilustra muy bien, se dieron a lo largo de la propia costa. De nuevo encontramos evidencias de estos movimientos en la muestra que analizamos.

Entre la costa sur y la costa central se encuentran dos ejemplares (Nos. Cat. 112 y 113) que consisten en sendos grupos de bolsitas miniatura, algunas de ellas aún con su relleno. La comparación con el conjunto de Monte Grande (A.P. Rowe 1986: 172: figs. 15, 17 y 18) nos permite relacionarlas con el complejo funerario Nazca-Wari. No obstante, similares conjuntos 
aparecen en el material que acompañaba los fardos funerarios de Ancón excavados por Reiss y Stübel y estudiados por Desrosiers y Pulini (1992) y Kaulicke (1997). Se sitúan, por tanto entre estas dos áreas.

En lo que respecta a la costa central, contamos tan sólo con una pieza que forma parte de una falsa cabeza de madera, perteneciente a un bulto funerario (№ Cat. 114). El tocado que muestra esta cabeza es simple, de algodón y pintado con una sustancia roja. Lamentablemente no aporta datos suficientes para caracterizar las prácticas textiles de los valles centrales en estos siglos, aunque constituye un testimonio de la presencia del tejido en variados contextos rituales, como el funerario.

A continuación nos ocuparemos de las producciones de la costa norte durante el Horizonte Medio.

La fuerte influencia serrana que se aprecia en todos los aspectos de la producción textil de la costa sur centroandina disminuye considerablemente conforme nos movemos hacia el norte a lo largo de los valles costeros.

Los tejidos norteños mostraron desde sus primeros momentos un notable conservadurismo en cuanto a sus patrones técnicos, que se mantendrán a lo largo de los distintos periodos, desde los primeros hallazgos de Huaca Prieta y Pampa Gramalote (Bird et. al. 1985; Conklin 1974) en los Periodos Precerámico e Inicial (véase Fig. 2) hasta la presencia Inca a partir de 1470 (A.P. Rowe 1984; Jiménez 2001a; Jiménez et.al. 2002). La torsión S ó S2Z en los hilos de la urdimbre que será, salvo en parte de los tejidos moche (Jiménez 2000a y 2001, véase Cap. II) de algodón, el uso restringido de la fibra de camélido a excepción siempre de los tejidos de lujo y la preferencia por el tapiz ranurado frente al entrelazado, se encuentran entre las convenciones técnicas más importantes. La influencia Wari en la decoración de los tejidos se aprecia más por cambios en los modos de representación, algo más abstractos y geométricos y la introducción de detalles, por ejemplo, en la indumentaria de los personajes, que por la presencia de motivos nuevos. De hecho, la abstracción geométrica serrana que se da en tapices producidos en la costa sur no la encontramos, sino de forma muy atenuada en la costa norte.

La consistencia de los procedimientos técnicos a lo largo de los distintos valles de la costa norte, nos impide apreciar con claridad las distintas producciones que debieron existir en esta extensa área. Ya vimos cómo en los valles meridionales era posible distinguir entre los tapices de iconografía y técnica Wari fabricados en la costa de otras producciones costeñas como las bandas decorativas con motivos costeños (aves con cabezas-trofeo, etc.) o las bandas de cabeza de iconografía tiwanacoide y técnica serrana fabricadas en la costa. En la costa norte podemos diferenciar también distintos "tipos" de tejidos, aunque los límites entre ellos son más difusos y se hace más complicado diferenciar, especialmente a la hora de incluir una pieza en un grupo u otro. Todos ellos, no obstante, tienen en común los elementos técnicos que hemos mencionado anteriormente y un "aire Wari” en las representaciones, que, por lo general, reflejan motivos pertenecientes a la imaginería norteña, como el cangrejo o los peces manta-raya y personajes con dos bastones y tocado prominente. Lamentablemente se trata de piezas de las que se han rescatado pocos ejemplares debido a problemas de conservación y de los que existe un número relativamente escaso en las colecciones públicas y privadas del mundo, la mayor parte de ellos, por otro lado, sin contexto arqueológico conocido.

Esta diversidad de producciones textiles se refleja en nuestro conjunto, en el que hemos incluido diez tejidos de diversas épocas y estilos (Nos. Cat. 115-125), desde el más temprano, Moche-Wari (№ Cat. 115), hasta las primeras manifestaciones Lambayeque o Sicán a finales del Horizonte Medio (Nos. Cat.119-122) y un grupo de cinco tejidos (Nos. Cat. 116-118 y 123 124), clasificados como "Horizonte Medio costa norte. Finalmente incluimos aquí un ejemplar, el № Cat. 125, que hemos asignado a la costa 
central, pero que se relaciona estrechamente con sus contemporáneos norteños.

El más temprano, decíamos, es un tejido inacabado que hemos clasificado como MocheWari (№ Cat. 115) y procede, según los datos de la Ficha de Inventario, de Trujillo, en la costa norte peruana, uno de los centros más importantes de la entidad mochica. El análisis técnico de este ejemplar indica que el patrón de torsión de las urdimbres, S2Z, es típico de Moche, mientras que la técnica de tapiz ranurado en la variedad dovetailing será una influencia introducida en el estilo Moche Tardío o Moche-Wari (Jiménez 2001). El motivo zoomorfo pertenece también a la imaginería norteña, aunque el estilo de representación muestra cierta abstracción geométrica que se aleja del claro realismo que caracteriza a los tejidos Moche de fases anteriores. En términos generales, este ejemplar muestra la menor permeabilidad que presentó la tradición norteña hacia la influencia Wari en comparación con el estilo Nazca y en general las producciones textiles de la costa sur (vid supra). En nuestra Memoria de Licenciatura (Jiménez Ibid) analizamos con detenimiento las transformaciones sufridas por el estilo textil Moche en su última fase, que ocupó la primera parte del Horizonte Medio. Del mismo modo que sucede con NazcaWari, los tejidos Moche Tardío que ilustra el ejemplar que analizamos aquí, suponen una evolución de los patrones Moche junto con influencias estilísticas y técnicas durante estos siglos de cambios.

A finales del Horizonte Medio e inicios del Periodo Intermedio Tardío (aprox. 850-1100 d.C.), se siguen notando las reminiscencias Moche en tejidos que sin embargo, estilísticamente ya no pueden considerarse dentro de este grupo.

Esas reminiscencias se funden con elementos altiplánicos. Así lo refleja la segunda de las piezas que analizaremos (№ Cat. 116). Esta pieza, que fue anteriormente analizada por nosotros (Jiménez 2000: 237-238, fig. 6), constituye un interesante ejemplo de las intensas relaciones existentes entre comunidades de distintas regiones del área andina.

Según los datos del Museo, procede del valle de Nazca, en la costa sur, pero en nuestra opinión fue fabricada en la costa norte y después viajó dentro de las redes de redistribución e intercambio, hasta las áreas meridionales de la costa centroandina.

La iconografía de esta banda une el desarrollo de Moche, con el posterior Chimú, recogiendo al tiempo la influencia Wari (Figura 11). En concreto hay dos motivos que podemos encontrar en esta banda-muestrario y que aparecen también en un tejido Chimú Temprano de esta colección que analizaremos después con detenimiento (№ Inv. 198). Se trata de un motivo de peces entrelazados formando hileras verticales y de un motivo geométrico similar que podrían ser igualmente peces entrelazados en una versión estilizada, que enmarcan esta franja y ocupan una de las secciones decoradas de la bandamuestrario. La primera de ellas puede relacionarse con el estilo Moche, mientras que la segunda responde más bien a la influencia Wari.

En la época de transición hacia el Periodo Intermedio Tardío hemos situado algunos ejemplares, también pertenecientes a la tradición norteña, que comentaremos a continuación, ya que consideramos que su vinculación con este periodo los hace más cercanos a Wari que a los del siguiente periodo cronológico. Nos referimos a los Nos. Cat. 116-118 y 123-124.

La influencia serrana en las técnicas norteñas fue muy sutil, a pesar de lo que el procedimiento de "atado y teñido" (tye-dyed) que tuvimos oportunidad de ver como parte de los tejidos de lujo en la costa sur, se da en algunos ejemplares de la costa norte de los que poseemos uno en nuestra muestra (№ Cat. 117). La particularidad regional más importante que presentan estos "tie-dyed" norteños es el uso exclusivo de fibra de algodón de mucha mayor finura que en los sureños fabricados por otra parte de fibra de camélido y la característica torsión en "S" de estos hilos. Otras diferencias son la gama de colores, que es 
apagada en comparación con los brillantes colores del sur y el menor tamaño de los rombos a partir de los cuales se forman los diseños. Este es un rasgo que, en nuestra opinión, supone una evolución estilística con respecto a los diseños anteriores. Los tejidos decorados mediante este procedimiento no fueron comunes en contextos de la costa norte. Uno de los pocos hallazgos documentados es el de siete piezas en el sitio El Castillo del valle nor-costeño de Huarmey (Pruemers 2000: 303, fig. 21). Durante el Intermedio Tardío (1000-1450 d.C.) estos tejidos casi desaparecen de los valles septentrionales. Ningún tejido tye-dyed forma parte de los hallazgos de Las Avispas (A.P. Rowe 1980) ni de la caracterización del estilo Chimú que realiza esta autora (ibid, 1984). Nosotros no hemos documentado ninguno en cuatro años de excavaciones en el sitio Chimú de Farfán (Jiménez 2000d, 2002b y Jiménez et al. 2002).

El carácter fragmentario del ejemplar del Museo de América hace imposible identificar su función. Otras piezas documentadas con similares características (Bjerregaard 2002: 66, $\mathrm{n}^{\text {o }}$ 0.4202; Stone-Miller, ed. 1992: 230, no 148), así como una de mayor tamaño perteneciente a la Colección Maiman y estudiada por nosotros (Makowski et al. en prensa), indican que su uso fue distinto al que se hizo en la costa sur, donde, como vimos, formaron parte de la indumentaria de individuos masculinos de élite. En este caso, quizá la decoración de muros o el uso como tocado, quizá femenino, son posibles propuestas, aunque éstas tienen un carácter tentativo dada la falta de datos hasta el momento.

Otro tipo de tejidos que se darán en el área norteña y central-norteña a finales del Horizonte Medio y comienzos del Intermedio Tardío son los tejidos pintados. En nuestro conjunto hay dos ejemplares de diferente carácter que ilustran este fenómeno (Nos. Cat. 118 y 124). El primero de ellos muestra unos personajes ataviados con un gorro Wari y orejeras, muy similares a los representados en la cerámica de sitios como el Complejo El Brujo, en el norteño valle de Chicama (Rodman y Fernández 2000: fig. 23). El otro tipo de tejido tiene unos diseños incompletos, aparentemente zoomorfos de difícil identificación. Lo más destacable de estos tejidos es que ilustran diferentes técnicas de pintado. El primero de ellos muestra un trazo preciso y estrecho, en un solo color marrón, posiblemente aplicado con una caña u otro objeto plano y rígido, mientras que el segundo tiene un trazo grueso en colores azulados y pudo haberse realizado con una especie de pincel. Este último se acerca más a los tejidos encontrados en diferentes sitios de la costa central y centro-norte, como Chimú Cápac (Oakland y Fernández Ibid: figs. 20-22) y de los valles más septentrionales de la costa norte, como Pacatnamú.

Dentro del grupo genérico de "Horizonte Medio Periodo Intermedio Tardío costa norte" se encuentra un ejemplar procedente de Trujillo (Figura 12) que es una buena ilustración de la dinámica de intercambio de productos e ideas a lo largo de la costa norte y central en la transición entre estos dos periodos. El análisis técnico evidenció que fue tejido con las urdimbres en horizontal, un rasgo característico de la tradición textil serrana y que se detecta en la costa durante el Horizonte Medio. Esta pieza, que hemos situado a finales de ese periodo y comienzos del Intermedio Tardío, muestra la tenue influencia Wari en la costa norte que pasará a formar parte de los estilos textiles de los siglos siguientes. En trabajos anteriores en los que nos hemos ocupado extensamente de ella (Jiménez 2000b: 239. 242, fig. 7), demostramos que formó parte de un tipo textil producido en la costa septentrional centroandina y que se incluyó dentro de las redes de intercambio que unieron los distintos valles costeros. Sus patrones técnicos e iconográficos muestran una notable estandarización y la iconografía (véase Fig. 12) se relaciona con los cultos regionales que parecen haber sufrido un impulso en relación a la distribución del complejo del "Dios de los Báculos" que mencionamos con anterioridad a lo largo y ancho de los Andes. Posiblemente un concepto común fue adoptado 
por las distintas tradiciones locales y dio como resultado personajes míticos identificados a un tiempo con las creencias de la región y con un culto de carácter "panandino".

Pasando a otro grupo incluido en este lapso temporal nos ocuparemos de lo que quizá se encuentre entre los fenómenos más destacables de la producción textil norteña de finales del Horizonte Medio. Nos referimos al surgimiento del estilo Lambayeque o Sicán de la mano de una cultura definida por Shimada (1995) y que se centró en la parte norteña de la costa norte (véanse Figs. 2a y 3). El desarrollo cronológico Lambayeque o Sicán se extiende desde el final del Horizonte Medio hasta la mitad del Periodo Intermedio Tardío (véase Fig. 2). En concreto, Shimada (ibid) ha establecido tres fases: Sicán Temprano (700 900 d.C.), Sicán Medio (900 1100 d.C.) y Sicán Tardío (1100 1350 d.C.). El complejo ideológico Wari tuvo una fuerte influencia en el estilo Lambayeque o Sicán, que aunó estos influjos con los elementos del anterior estilo Moche y de la tradición norteña en general. Estos rasgos serranos están muy presentes en los tejidos Lambayeque/Sicán del Museo de América de Madrid, de modo que hemos considerado más idóneo tratarlos en conjunto con el resto de los tejidos norteños del Horizonte Medio. Estas piezas constituyen el puente hacia el posterior periodo en el que eclosionará el estilo Chimú con el que Lambayeque/Sicán tuvo en sus inicios una importante relación. Pensamos, por tanto, que su inclusión dentro de los tejidos del Horizonte Medio nos da la posibilidad de observar el continuum cultural de esta región de la costa centroandina.

Nosotros hemos clasificado como Lambayeque o Sicán cuatro ejemplares (Nos. Cat. 119-122). Todos ellos son técnicamente tejidos norteños: poseen urdimbres de algodón con torsión S ó S2Z, tramas de algodón y fibra de camélido en la dirección contraria y están trabajados en tapiz de ranuras. Dado que se trata de tejidos de lujo, no muestran la característica restricción de fibra de camélido que se observa en otros tejidos Lambayeque o Sicán de calidad media, como los que documenta Boytner (1998) en el sitio de Pacatnamú. Dos de ellos (Nos. Cat. 119 y 120) (Figura 13) muestran una escena típica de este estilo, en la que varios personajes ataviados con grandes tocados y camisas decoradas, portan bastones o, en el segundo caso, una cabeza-trofeo y están alineados en horizontal y situados sobre o bajo estructuras.

A pesar de las diferencias formales entre ambos tapices, es fácil identificar la misma escena en ambos, lo que indica una fuerte estandarización. En su estudio de las deidades Lambayeque o Sicán y Chimú, Carol Mackey (2001: 155-156) ha señalado que las primeras se adaptaron a cada soporte particular, de modo que, si bien el mismo tema se dio en textiles (Mackey 2001: 125, figs. 15 a y 15b; 128, fig. 20), metales (Cordy-Collins 1996: 214 fig. 83, 215-216, pl. 52), murales (Alva y Meneses 1983), etc., existieron detalles que variaron entre ellas. Este hecho es interpretado por la Mackey como un grado menor de estandarización con relación a Chimú, que constituyó un imperio más fuerte y unificado que la entidad lambayecana. La interpretación de estas figuras puede variar aunque nosotros pensamos con Alva y Meneses (ibid) que se trata de diferentes personajes o deidades y que se ha representado ex profeso esta diferencia. En efecto, en los tejidos Lambayeque/Sicán de nuestro conjunto, las figuras se diferencian entre sí por elementos claros como la decoración de sus camisas.

El segundo de estos tejidos (№ Cat. 120) destaca además por su tipología, pues se trata de un muestrario de diseños. Es una de las piezas más sobresalientes de la Colección y de ella nos ocupamos anteriormente en profundidad (Jiménez 2000b: 243-245, fig. 8). Su decoración muestra de nuevo a estos personajes frontales, aunque con menores atributos de rango y con una llamativa variante: la presencia de lo que parecen ser cabezas-trofeo agarradas en una mano. Se trata, por tanto, de la variación de una misma idea que, en este caso, estaba siendo "ensayada” por la teje- 
dora. Los otros dos tejidos de este estilo (Nos. Cat. 121 y 122) son de un tipo particular de bordes o aplicaciones que se han documentado especialmente en tejidos del sitio de Pacatnamú (valle de Jequetepeque) (Boytner 1998a; Keatinge 1978). Tejidos de Lambayeque o Sicán se han hallado también en Pachacamac, a consecuencia del tráfico intenso de personas y bienes existentes entre Pacatnamú y el oráculo de la costa central (Bjerregaard 2002: 55-57, Keatinge 1978).

Para terminar esta parte queremos referirnos, siquiera brevemente al ejemplar № Cat. 125 , que muestra una iconografía perteneciente al mismo complejo ideológico expresado en el tejido № Cat. 123 e incluso de Lambayeque/ Sicán, aunque más emparentada con la costa central. En efecto, el análisis de sus rasgos indica que pudo haberse fabricado en la costa central o norte. Sin embargo la iconografía refleja un tema frecuente en los tejidos norteños, por lo que ha de ser incluido en este grupo. El peso de la tradición norteña está patente en esta pieza que, además, pone de manifiesto los intensos contactos que se dieron entre distintas tradiciones regionales costeñas.

Como conclusión de las anteriores páginas parece quedar la idea de que a lo largo del Horizonte Medio y durante el lapso transcurrido entre su fin y los comienzos del Intermedio Tardío, la producción textil de la costa norte se caracterizó por la variedad y esa mezcla de tradiciones locales e influencias serranas que ya vimos en la costa sur. Se consolida así la idea del Horizonte Medio como periodo de intenso movimiento de ideas, poblaciones y objetos y el importante papel del tejido como expresión de esta dinámica.

Hasta aquí hemos repasado las evidencias textiles presentes en la Colección del Museo de América del Horizonte Medio en el área central andina.

Las diferentes variantes regionales dibujan un panorama muy complejo en el que se puede apreciar un distinto grado de influencia serrana en unas áreas con respecto a otras. Hay que tener en cuenta, no obstante, que el conjunto que hemos analizado muestra una clara descompensación de los fondos a favor de la costa sur. La costa norte y central están representadas por escasas piezas que son en todo caso un tímido aunque expresivo testimonio de esta variedad, mientras que no poseemos ninguna pieza asignable a los desarrollos de la sierra central y norte durante estos siglos.

También hay que mencionar que estas piezas muestran la producción más fina y de mayor belleza y que no están representadas prendas y otros objetos textiles destinados a la vida diaria que iluminarían uno de los aspectos menos conocidos de estos periodos prehispánicos.

Contando con estos obstáculos hemos ofrecido una síntesis analítica que, en nuestra opinión, ayuda a comprender estos siglos tan importantes del Periodo Prehispánico.

\section{Bibliografía}

\section{Alva, Walter y Susana Meneses}

1983 "Los murales de Úcupe en el valle de Zaña, norte del Perú". Beitrâge zur Allgemeinen und vergleichenden archâologie, 5: 335-360. Bonn : Komission für allgemeine und vegleichende archâologie des Deutschen archâologischen Instituts.

Berenguer, José R.

1993 "Gorros, identidad e interacción en el desierto chileno antes y después del colapso de Tiwanaku", en Identidad y prestigio en los Andes. Gorros, turbantes y diademas, pp. 41-61. Santiago de Chile: Museo Chileno de Arte Precolombino.

Bird, Junius y Milica Dimijitrevic

1974 "The technical features of a Middle Horizon tapestry shirt from Peru". The Textile Museum Journal, IV (1): 5-13, Washington, D.C.: The Textile Museum. 
Bird, Junius, et.al.

1981 Museums of the Andes. Great Museums of the World. Nueva York: Neewsweek.

Bjerregaard, Lena

2002 Precolumbian woven treasures in the National Museum of Denmark. Copenhague: The National Museum of Denmark y Union Académique Internationale.

Bouysse-Cassagne, Thérèse

1997 "Plumas: signos de identidad, signos de poder entre los Incas", en Homenaje a María Rostworowski, Rafael Varón y Jorge Flores eds., pp. 545-566. Lima: Instituto de Estudios Peruanos (IEP).

Boytner, Ran

1998 "The Pacatnamu Textiles: a study of identity and function". Tesis Doctoral Departamento de Antropología. University of California Los Angeles. Manuscrito.

Cabello, Paz

1989 Coleccionismo americano indígena en la España del siglo XVIII. Madrid: Ediciones de Cultura Hispánica, Agencia Española de Cooperación Internacional. Ministerio de Asuntos Exteriores.

1994 El Museo de América. Madrid: Dirección General de Bellas Artes, Ministerio de Cultura.

Conklin, William

1974 "Pampa Gramalote textiles", en The Irene Emery Roundtable on Museum Textiles, 1974 Proceedings, Archaeological Textiles, Patricia Fiske ed., pp. 77-92. Washington D.C.: The Textile Museum.

Conklin, William, et al.

1996 "Nazca/Wari and other south coast textiles", en Andean Art at Dumbarton Oaks, Vol. 2. Elizabeth H. Boone ed., pp. 413-423. Washington D.C.: Dumbarton Oaks Library and Research Collection.

Cook, Anita G.

1996 "The Emperor's new clothes: symbols of royalty, hyerarchy and identity". Journal of the Steward Anthropological Society, 24, (1 y 2$): 85-120$.

Cordy-collins, Alana

1996 "Lambayeque", en Andean Art at Dumbarton Oaks. Vol. 1 Elizabeth Boone ed., pp. 189-222. Washington D.C.: Dumbarton Oaks Research Library and Collection.

Cornejo, Luis E.

- "Estableciendo diferencias: la representación del orden social en los gorros del periodo Tiwanaku", en Identidad y prestigio en los Andes. Gorros, turbantes y diademas, Francisco Gallardo et al., pp. 27 40. Santiago de Chile: Museo Chileno de Arte Precolombino.

Desrosiers, Sophie e Ilaria Pulini

1992 Tessuti precolombiani. Musei Civici di Modena. Modena: Ediciones Franco Cossimo Panini.

Écija, Ana y Ana VERDE

2000 "La colección de textiles andinos precolombinos y coloniales del Museo de América de Madrid", en Actas de la I Jornada Internacional sobre Textiles Precolombinos, Victòria Solanilla ed., pp. 57-65. Barcelona: Universitat Autònoma de Barcelona, Departament d'Art e Institut Català de Cooperació Iberoamericana.

Frame, Mary

1986a "The visual images of fabric structures in ancient peruvian art", en The Junius B. Bird Conference on Andean Textiles, A.P. Rowe ed., pp. 47-81. Washington, D.C.: The Textile Museum.

1986b "Nazca sprang tassels: Structure, technique and order". The Textile Museum Journal 25: 67-82. Washington D.C.: The Textile Museum.

1990 Andean four-cornered hats. Ancient volumes. Nueva York: The Metropolitan Museum of Art.

1996 "Late Nazca tassels" en Andean Art at 
Dumbarton Oaks, Vol. 2. E. Boone ed., pp. 365-373. Washington D.C.: Dumbarton Oaks Research Library and Collection.

1999b "Textiles de Estilo Nazca" / "Nazca Style textiles" en Tejidos Milenarios del Perú /Ancient Peruvian Textiles, Jose A. Lavalle y Rosario de Lavalle eds., pp. 261-310. Lima: AFP. Integra y Wiese Compañía de Seguros.

1999c"Nazca-Wari y otros textiles de la costa sur" / "Nazca-Wari and other South Coast textiles", en Tejidos Milenarios del Perú /Ancient Peruvian Textiles, Jose A. Lavalle y Rosario de Lavalle eds., pp. 311-352. Lima: AFP Integra y Wiese Compañía de Seguros.

D' Harcourt, Raoul

1934 Des Textiles anciens des Pérou et leurs techniques. París: Les Editions d'Art et d'Historie.

1962 Textiles of ancient Peru and their techniques. Washington, D.C.: University of Washington Press.

Jiménez, María Jesús

2000a "Los tejidos Moche de Dos Cabezas (Valle de Jequetepeque): hacia una definición del estilo textil mochica", en Actas de la I Jornada Internacional sobre Textiles Precolombinos, Victòria Solanilla ed., pp. 76-96. Barcelona: Universitat Autònoma de Barcelona, Departament d'Art e Institut Català de Cooperació Iberoamericana.

2000b "Los tejidos prehispánicos del Museo de América y la reconstrucción del pasado andino". Anales del Museo de América 8: 225-272. Madrid: Ministerio de Cultura.

2001a Los tejidos Moche de Dos Cabezas (Valle de Jequetepeque, Perú): Avances en la caracterización del Estilo Textil Mochica. Memoria de Licenciatura presentada en el Departamento de Historia de América II (Antropología Americana). Universidad Complutense, Madrid.

En prensa Catálogo de la Colección Textil del Museo de América

Jiménez, María Jesús, et al.

2002 "Los tejidos Chimú/Chimú-Inca del valle de Jequetepeque (Perú): Pervivencias y Cambios en la Textilería Norteña Tardía", en Actas de las II Jornadas Internacionales sobre Textiles Precolombinos. Victòria Solanilla ed., pp. 235-250. Barcelona: Universitat A u tòn o m a d e B a r c elon a , Departamento de Arte e Institut Català de Cooperación Iberoamericana.

Kaulicke, Peter

1997 Contextos funerarios de Ancón. Esbozo de una sintesis analítica. Lima: Pontificia Universidad Católica del Perú, Fondo Editorial.

Keatinge, Richard W.

1978 "The Pacatnamu Textiles". Archaeology 31 (2): 28-41. NuevaYork.

Mackey, Carol

2001 "Los dioses que perdieron los colmillos", en Los dioses del antiguo Perú, Vol. 2, K. Makowski ed., pp. 111-158. Lima: Banco de Crédito del Perú.

Makowski, Krzyzstoff, et. al.

En prensa Catálogo de la Colección Maiman de Tejidos Precolombinos

Menzel, Dorothy

1964 "Style and time in Middle Horizon". Nawpa Pacha 4: 1-107. Berkeley: University of California.

1977 The archaeology of Peru and the work of Max Uhle, Berkeley: R.H. Museum of Anthropology, University of California.

Rodman, Amy O. y Arabel Fernández

2000 "Los tejidos Wari y Tiwanaku: comparaciones y contextos", Wari y Tiwanaku: Modelos vs. evidencias, Primera Parte. 
Boletín de Arqueología PUCP 4: 119-130.

Lima: Pontificia Universidad Católica del Perú.

O'neale, Lila M. y Clark

1948 "Textile periods in ancient Peru, Part III: The gauze weaves". University of California Pulications in American Archaeology and Ethnology 4: 143-222. Berkeley: University of California.

Pruemers, Heiko

2000 '"El Castillo' de Huarmey: una plataforma funeraria del Horizonte Medio". Wari y Tiwanaku: Modelos vs. evidencias, Primera Parte. Boletín de Arqueología PUCP 4: 289-312, Lima: Pontificia Universidad Católica del Perú.

Ramos, Luis

1973 Los tejidos preincaicos del Museo de América. Tesis Doctoral presentada en el Departamento de Historia de América II (Antropología de América), Universidad Complutense de Madrid. Manuscrito.

Rowe, Ann P.

1972 "Interlocking warp and weft in the Nazca 2 Style". The Textile Museum Journal III (3): 67-78. Washington, D.C.: The Textile Museum.

1977 Warp-patterned weaves in the Andes. Washington D.C.:The Textile Museum.

1979 "Seriation of an Ica-Style garment type" en The Junius B. Bird Precolumbian Textile Conference, A.P. Rowe et.al. eds., pp. 185-218. Washington D.C.: The Textile Museum and Dumbarton Oaks Trustees of Harvard University.
1980 "Textiles from the burial platform of Las Avispas at Chan-Chan". Nawpa Pacha 18: 81-150. Berkeley: University of California.

1984 Costumes and featherwork of the Lords of Chimor. The Textile Museum, Washington D.C.

Schlindler, Helmut

2000 La Colección de Robert Mayrock del Perú Antiguo. Munich: Staaliches Museum fur Völkerkunde.

Shimada, Izumi

1995 Sicán. Dios, poder y riqueza en la costa norte del Perú. Lima: Ediciones del Banco de la Nación.

Silverman, Helaine y Donald Proulx

2002 The Nazca. Cambridge: Blackwell Publishers Inc.

Solanilla, Victòria

1999 Tèxtils precolombins de colleccions públiques catalanes. Barcelona: Institut d'Estudis Catalans Stone-Miller, ed 1994

Stone-Miller, Rebecca (ed.)

1994 To weave for the Sun: ancient Andean textiles in the Museum of Fine Arts of Boston. Nueva York.: Thames and Hudson.

Strelow, Renate

1996 Gewebe mit unterbrochenen ketten aus dem vorspanischen Peru / Pre-Hispanic Peruvian with discontinuous warp and weft textiles. Berlín: Museum für Völkerkunde, Abteilung Amerikanische Archäologie.

Ulloa, Liliana

1985 Arica. Diez mil años. Santiago de Chile: Museo Chileno de Arte Precolombino. 

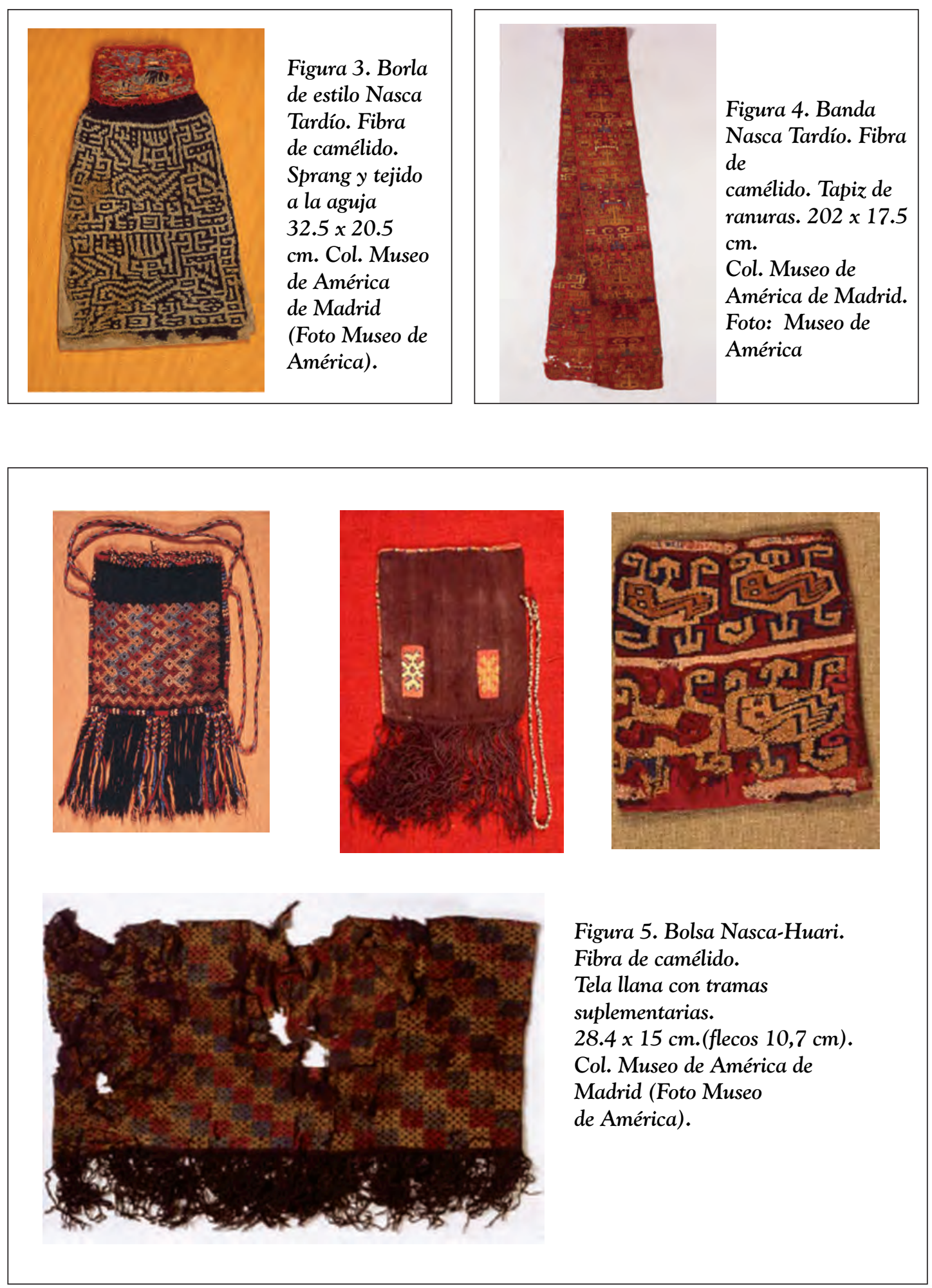
Figura 6. Borla de estilo Nasca Tardío. Fibra de camélido. Sprang y tejido a la aguja $32.5 \times 20.5 \mathrm{~cm}$. Col. Museo de América.
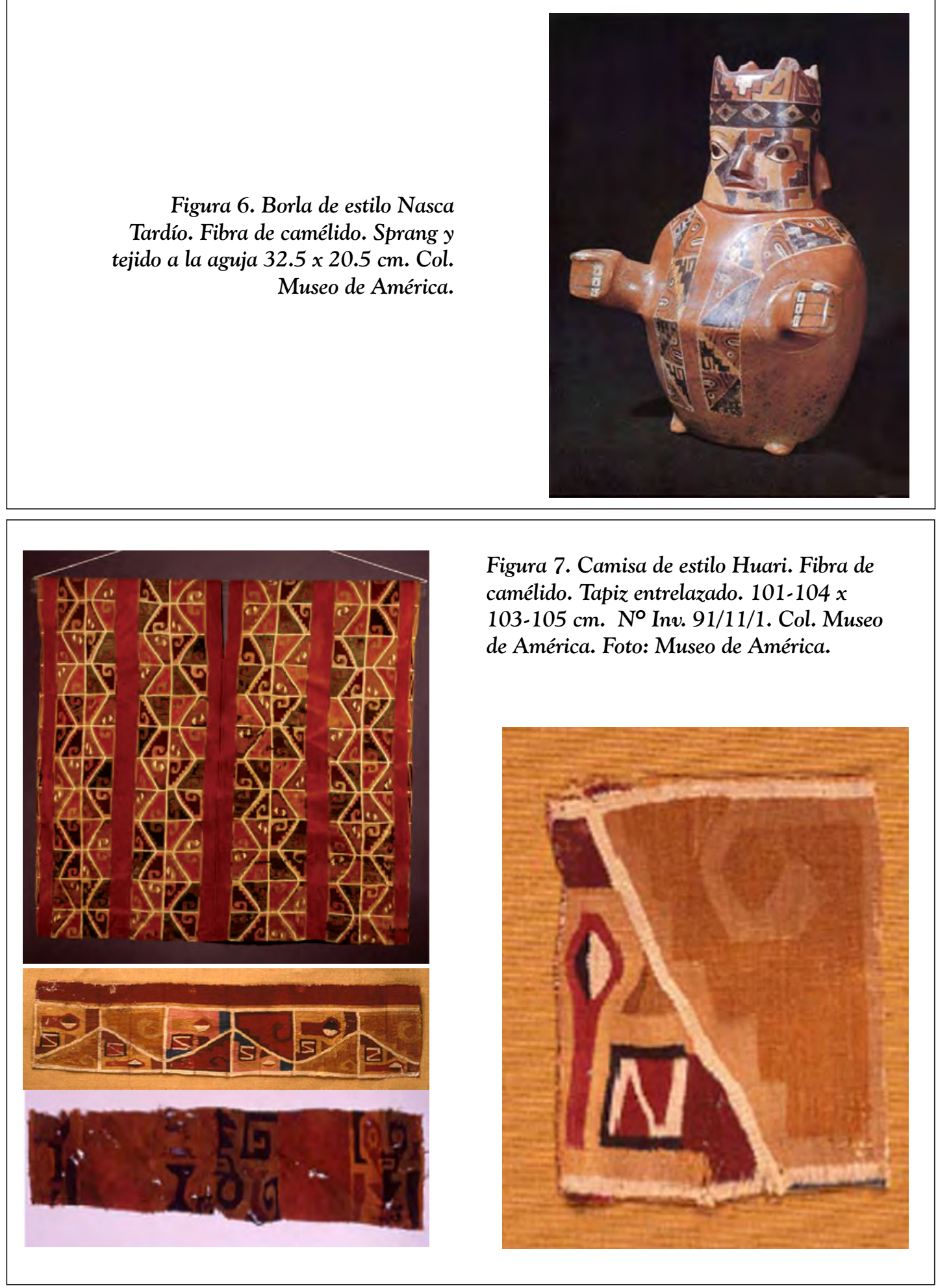


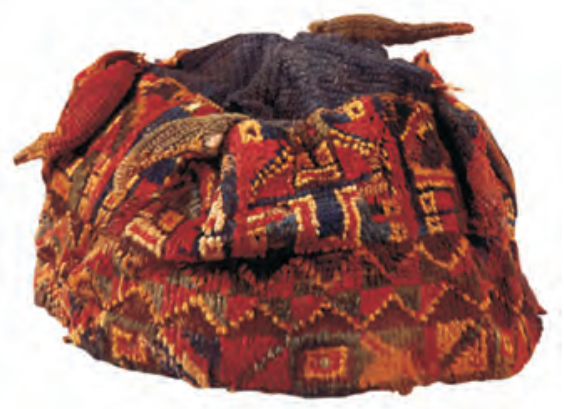

Figura 8: Gorro de cuatro puntas con representación de rombos cuatripartitos. Fibra de camélido. Anudado y tramas insertas a modo de terciopelo. Altura: $10 \mathrm{~cm}$; diámetro aprox.: $14.5 \mathrm{~cm}$; altura puntas: $5.5-6 \mathrm{~cm}$. №. Inv. 02-5-228). Col. Museo de América. Foto: Museo de América.

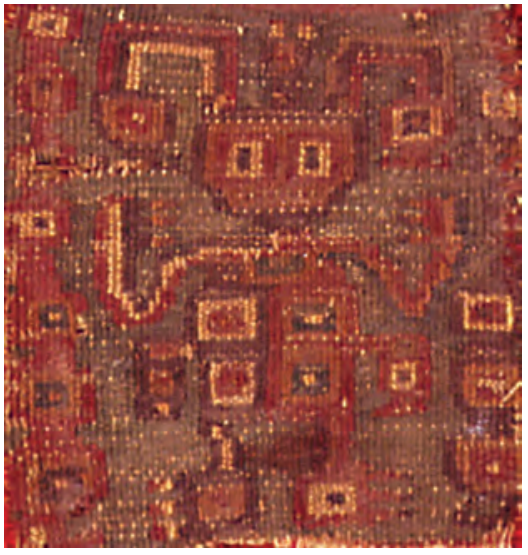

Figura 9. Detalle de banda con iconografía tiahuanacoide. Algodón y fibra de camélido. Tela llana con tramas suplementarias imitando tapiz. 36.8 $x 8.7 \mathrm{~cm}$. Col. Museo de América. Foto: Museo de América.
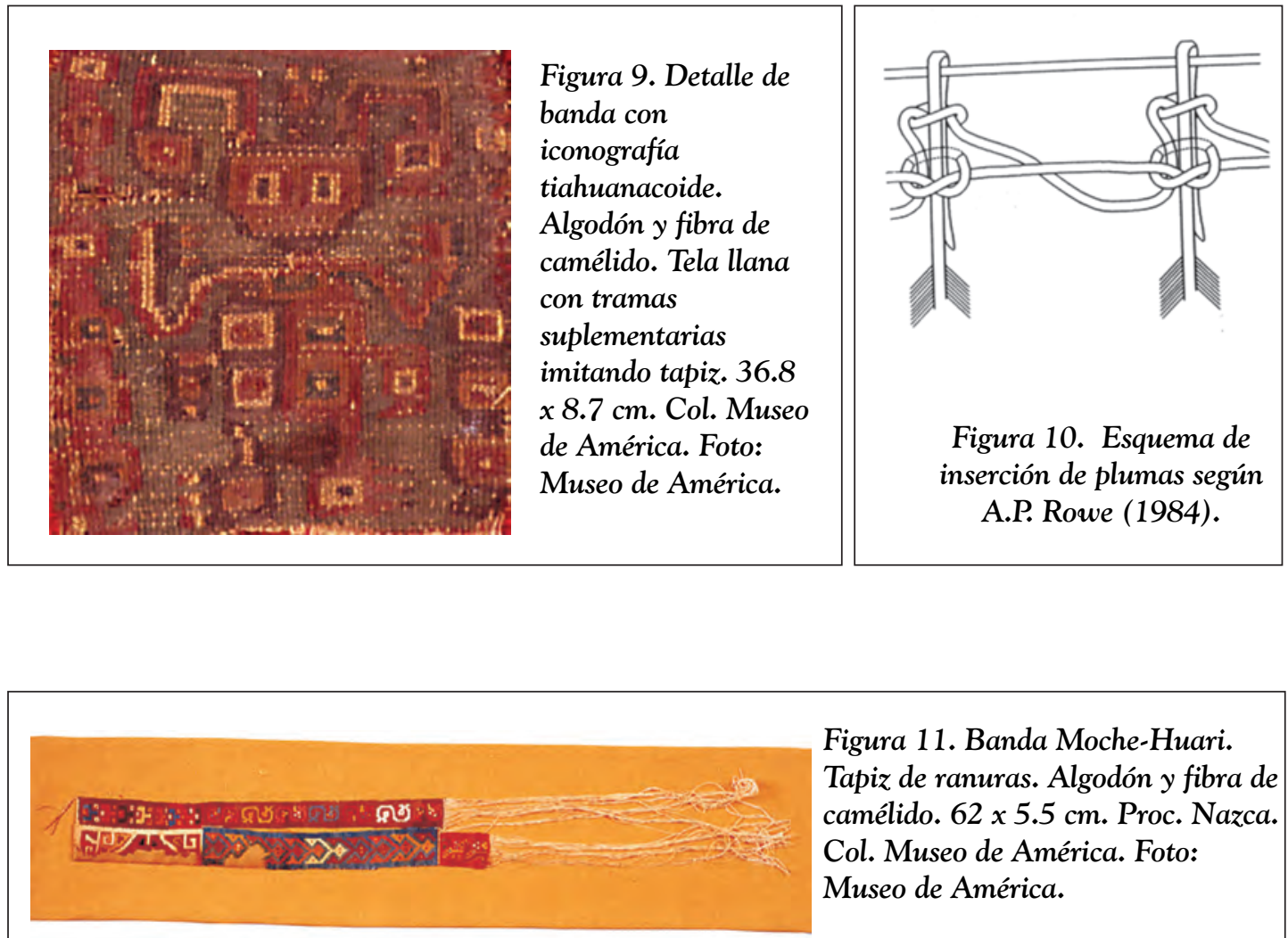

Figura 11. Banda Moche-Huari. Tapiz de ranuras. Algodón y fibra de camélido. $62 \times 5.5 \mathrm{~cm}$. Proc. Nazca. Col. Museo de América. Foto: Museo de América. 


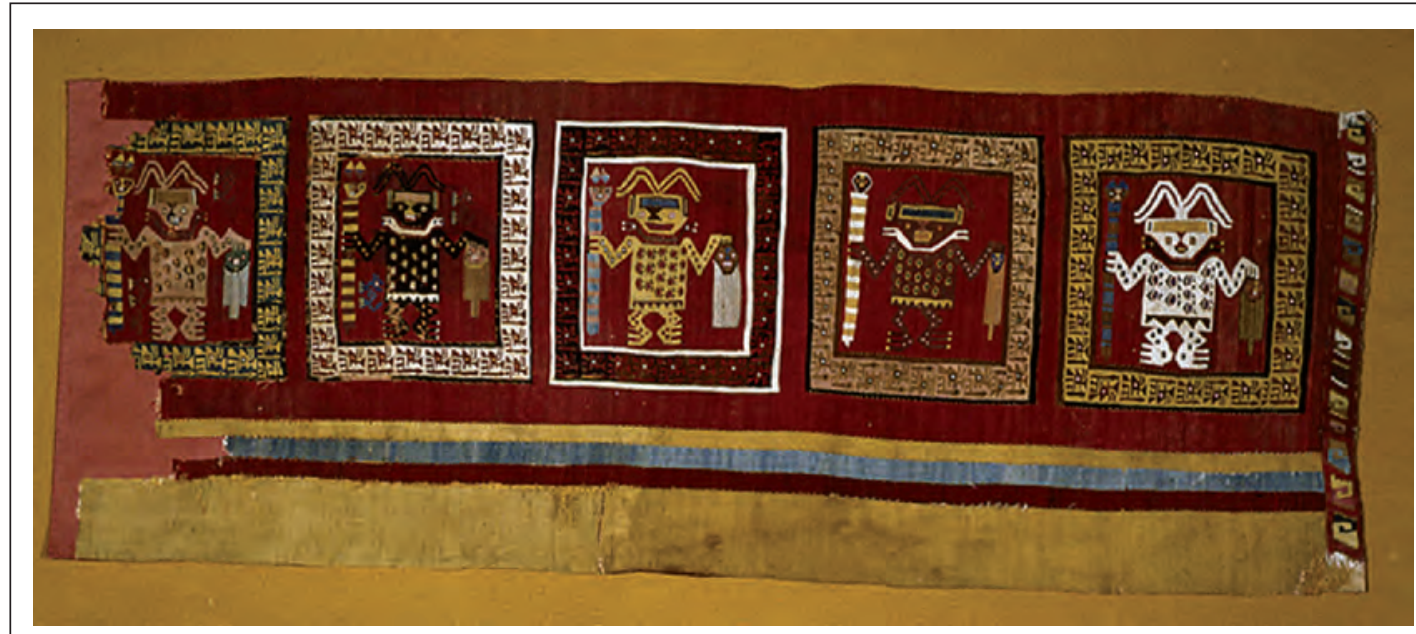

Figura 12. Fragmento de tejido de estilo norteño. Finales del Horizonte Medio-inicios del Intermedio Tardío. Tapiz de ranuras (ranuras cosidas). Algodón y fibra de camélido. $35 \times 84.5$ cm. Proc. Trujillo. Col. Museo de América. Foto: Museo de América
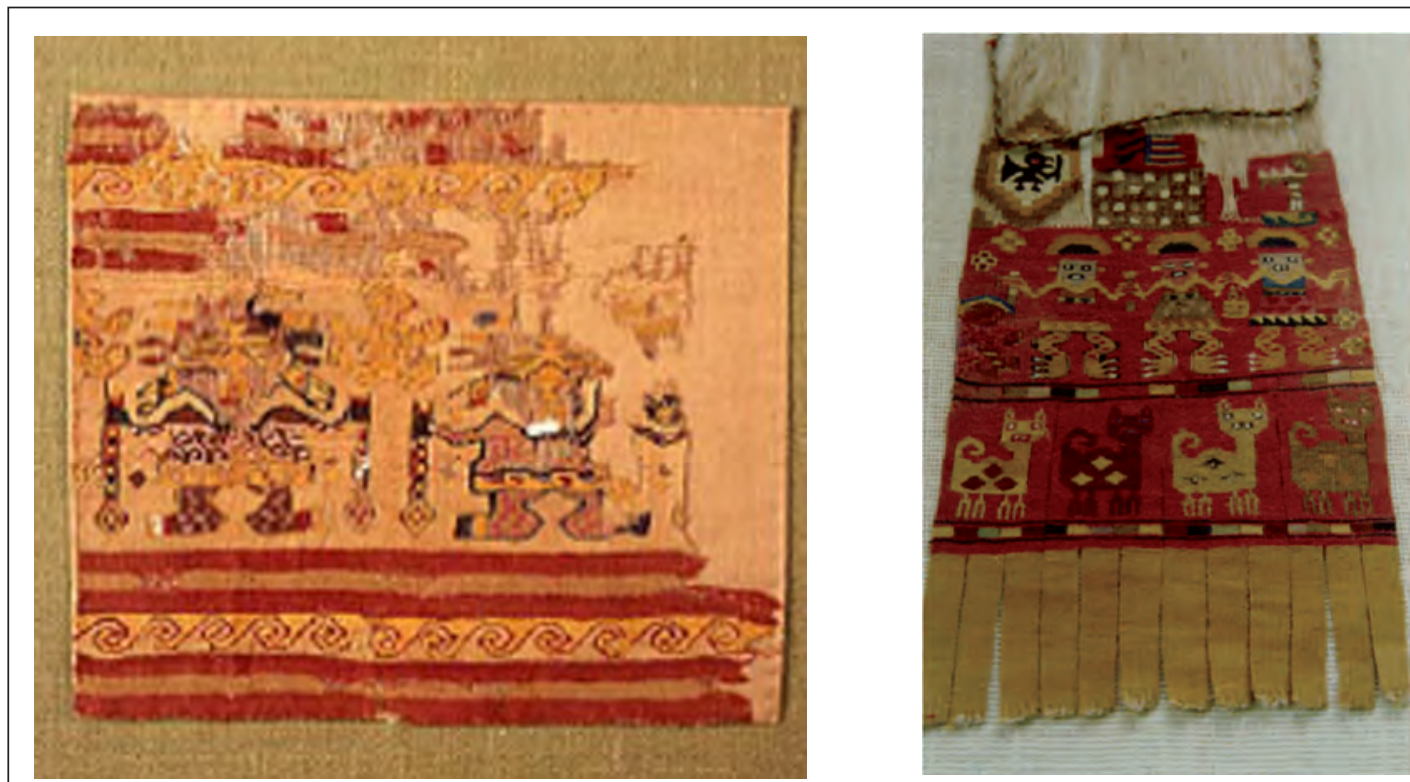

Figura 13: Muestrario Lambayeque o Sicán. Tapiz de ranuras. Algodón y fibra de camélido. $52.5 \times 17.5 \mathrm{~cm}$. Proc. Trujillo. Col. Museo de América. Foto: Museo de América. 